\title{
Capacitive Current Feedback Control Approach for LCL-Based Four Leg Shunt Active Power Filter
}

\author{
X. Du, J. Le, K.P. Liu \\ School of Electrical Engineering \\ Wuhan University \\ China
}

\begin{abstract}
The four leg shunt active power filter has strong ability of harmonic and neutral current compensation, and is especially suitable for three-phase four-wire system harmonic suppression. At present the single inductor filter is usually used in four leg shunt active power filter, but the single inductor filter does not have enough capacity for high frequency harmonic attenuation. Due to this, this paper proposes a three-phase four-leg applied to active power filter LCL filter. This paper proposes a LCL filter which is applied to three-phase four-leg active power filter. However, LCL filter can produce resonance. Series resistance in capacitor branch can inhibit resonance. As a result, it will consume more active power. So this paper proposed control strategy using capacitive current feedback, which can not only effectively suppress resonance but also avoid consuming active power.
\end{abstract}

Keywords-LCL filter; capacitive current feedback; four leg shunt active power filter; harmonic

\section{INTRODUCTION}

The single inductor filter is usually used in four leg shunt active power filter, but the single inductor can't effectively suppressing high frequency harmonics. In the case of equal inductance LCL filter has stronger ability of harmonic attenuation [1, 2]. [3, 4] proposed an approach of adding a series resistor in capacitor branch. But it will cause more active power consumption, which will reduce the system efficiency. [5, 6] proposed an strategy of using capacitive current feedback in LCL filter, but it does not specify the method, of which applying LCL filter in the four leg shunt active power filter. This paper firstly proposed the topology of LCL filter which was applied in four leg shunt active power filter, and then used capacitive current feedback to suppress resonance. Finally, simulation results show the effectiveness of the proposed algorithm.

\section{Four Leg Shunt Active POWER Filter TOPOlogy}

Thanks to the neutral line, the three phase four leg shunt active power filter outputs compensation current, which actually is the phase current. So we proposed the topology of three phase four leg shunt active power filter, as shown in Figure 1. $e_{a}, e_{b}, e_{c}$ are three phase source, $L_{s}$ is system inductance, $L_{1}$ is inductance beside the inverter, $L_{2}$ is inductance beside the grid, $C$ is capacitor filter, and $C_{d c}$ is capacitor in DC voltage bus.

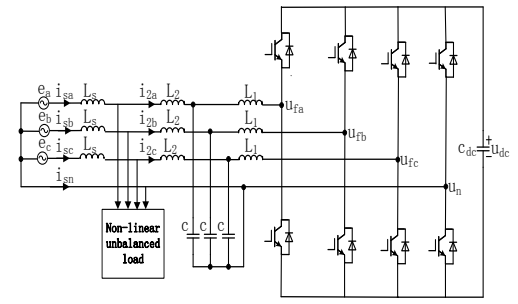

FIGURE I. .TOPOLOGY OF THREE PHASE FOUR LEG SHUNT ACTIVE POWER FILTER.

Firstly capacitor filter is connected in series in the source, so the capacitive reactance must be large enough. The capacitance value is designated as $3 \mu \mathrm{F}$ in this paper. $L_{l}$ is mainly decided to the request of harmonic content beside the inverter. $L_{2}$ is decided to the bypass capacitor and switching frequency. This paper the switching frequency is $10000 \mathrm{~Hz}$, so it would be better to design the resonant frequency at about $5000 \mathrm{~Hz}[7]$. The resonant angular frequency $\omega_{\text {res }}$ is calculated as formula 1.

$$
\omega_{\text {res }}=\sqrt{\frac{L_{1}+L_{2}+L_{s}}{L_{1}\left(L_{2}+L_{s}\right) C}}
$$

$L_{s}$ is $0.1 \mathrm{mH}$. Switching frequency $f_{s}=10000 \mathrm{~Hz}$, and $L_{l}$ is designed as $1 \mathrm{mH}$, so $L_{2}$ is designed as $0.5 \mathrm{mH}$. Pick out single phase circuit to analyze shown as figure 2 . Among them, $u_{i}$ is inverter output voltage, and $i_{2}$ is the compensation current.

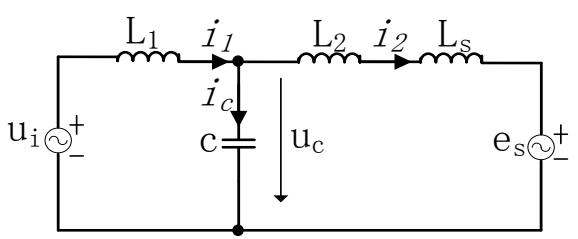

FIGURE II. SINGLE PHASE LCL FILTER EQUIVALENT CIRCUIT.

The transfer function $G(s)$ from $u_{i}$ to $i_{2}$ can be calculated as follows:

$$
G(s)=\frac{i_{2}}{u_{\mathrm{i}}}=\frac{1}{\left(L_{2}+L_{\mathrm{S}}\right) L_{1} C \mathrm{~s}^{3}+\left(L_{2}+L_{\mathrm{S}}+L_{1}\right) \mathrm{s}}
$$

The bode plot of the transfer function G(s) as is shown in figure 3 . 


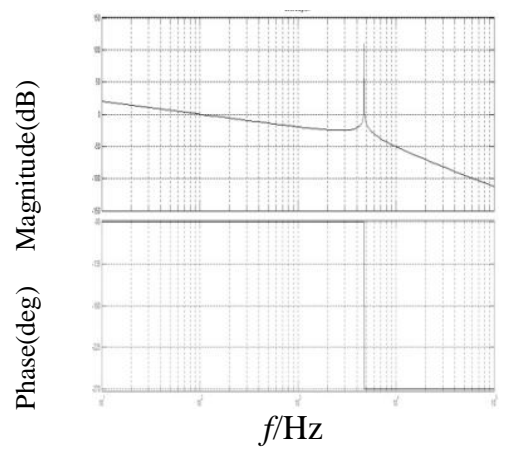

FIGURE III. BODE PLOT OF THE TRANSFER FUNCTION G(S).

As it can be seen from the bode diagram that there is a big resonant peak at about $4800 \mathrm{~Hz}$ in the case of undamped system, which will cause system instability.

\section{Capacitive CurRent Feedback Strategy}

Series resistance in capacitor branch can inhibit resonance[8]. As a result, it will consume more active power. So this paper has a detailed analysis of the LCL filtering principle, and proposed a strategy of using capacitive current feedback, which was also known as virtual resistance method[9]. It can not only effectively suppress resonance but also avoid consuming active power. Outer current loop uses PI control, and inner current loop uses capacitive current feedback control. The entire system control block diagram is shown below as figure 4 .

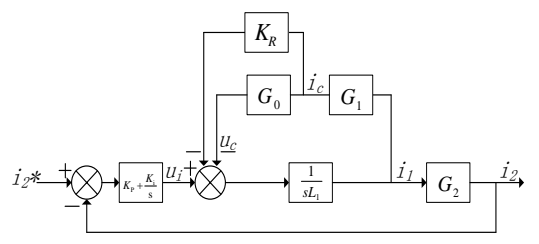

FIGURE IV. ENTIRE SYSTEM CONTROL BLOCK DIAGRAM.

$$
\begin{gathered}
G_{0}=\frac{u_{C}}{i_{c}}=\frac{1}{C \mathrm{~s}} \\
G_{1}=\frac{i_{c}}{i_{1}}=\frac{\left(L_{2}+L_{\mathrm{S}}\right) s}{\frac{1}{C s}+\left(L_{2}+L_{s}\right) s}=\frac{C\left(L_{2}+L_{\mathrm{S}}\right) s^{2}}{1+C\left(L_{2}+L_{\mathrm{S}}\right) s^{2}} \\
G_{2}=\frac{i_{2}}{i_{1}}=\frac{\frac{1}{C s}}{\frac{1}{C s}+\left(L_{2}+L_{s}\right) s}=\frac{1}{1+C\left(L_{2}+L_{\mathrm{S}}\right) s^{2}}
\end{gathered}
$$

Among them, the capacitive current proportional feedback $K_{R}$ is equal to virtual series resistance. The transfer function $W(\mathrm{~s})$ from $u_{i}$ to $i_{2}$ can be calculated as follows:

$$
W(s)=\frac{1}{\left(L_{1}+L_{2}+L_{\mathrm{s}}\right) s+K_{R} C\left(L_{2}+L_{\mathrm{s}}\right) s^{2}+C L_{1}\left(L_{2}+L_{\mathrm{s}}\right) \mathrm{s}^{3}}
$$

Setting $K_{R}$ for 5 . The bode plot of the transfer function $W(\mathrm{~s})$ as is shown in figure 5 .

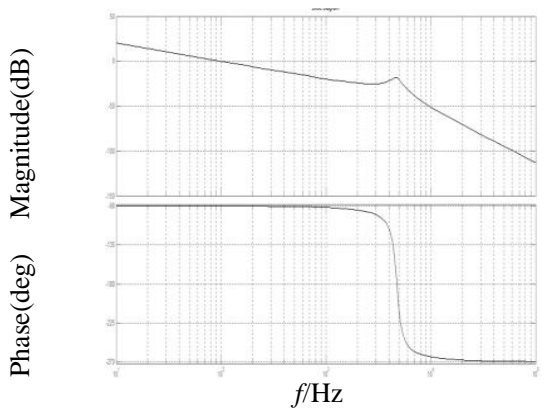

FIGURE V. BODE PLOT OF THE TRANSFER FUNCTION W(S).

As it can be seen from the bode diagram that the resonant peak is suppressed, which will ensure the stability of the LCL filter. Setting $K_{p}$ for 1 and $K_{i}$ for 1000 . Three phase non-linear unbalanced load topology are shown in the figure 6 .

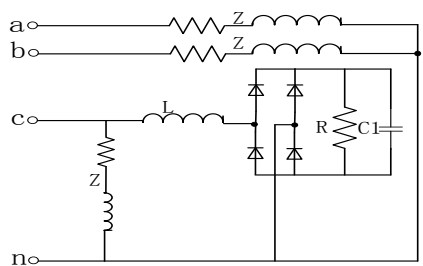

FIGURE VI. THREE PHASE NON-LINEAR UNBALANCED LOAD TOPOLOGY.

TABLE I .MAIN PARAMETERS.

\begin{tabular}{cc}
\hline Parameter & Value \\
& $1000 \mathrm{~Hz}$ \\
Switching frequency & $220 \mathrm{~V}$ \\
Phase voltage RMS & $0.1 \mathrm{mH}$ \\
$L_{s}$ & $1 \mathrm{mH}$ \\
$L_{l}$ & $0.5 \mathrm{mH}$ \\
$L_{2}$ & $3 \mu \mathrm{F}$ \\
$C$ & $600 \mathrm{~V}$ \\
$U_{d c}$ & $2200 \mu \mathrm{F}$ \\
$C_{l}$ & $10 \Omega+10$ \\
$\mathrm{Z}$ & $\mathrm{mH}$ \\
$\mathrm{R}$ & $8 \Omega$ \\
\hline
\end{tabular}

The load current waveform and source current waveform are shown below.

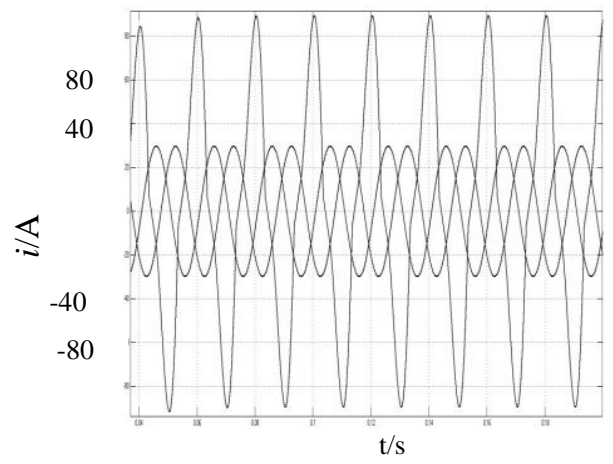

FIGURE VII. LOAD CURRENT WAVEFORM. 


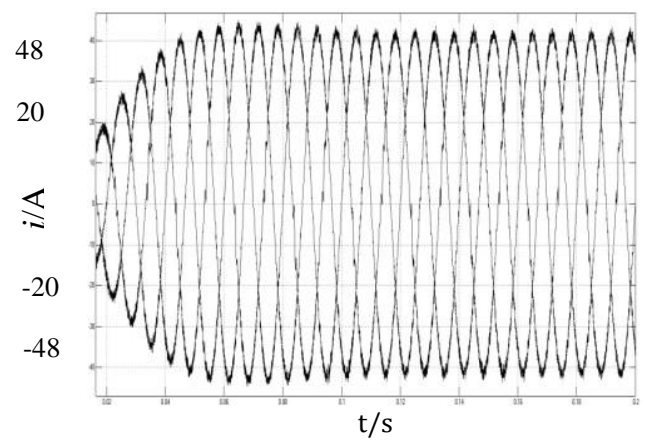

FIGURE VIII. THE SOURCE CURRENT WAVEFORM.

The amplitude and THD of source current after compensation are shown as table 2 .

TABLE II .SOURCE CURRENT ANALYSIS.

\begin{tabular}{cccc}
\hline Content & \multicolumn{3}{c}{ Phase } \\
\hline & $\mathrm{A}$ & $\mathrm{B}$ & $\mathrm{C}$ \\
& 41.6 & 41.5 & 41. \\
Phase &. & $1.95 \%$ & 4 \\
Amplitude/A & 1.98 & & 3.4 \\
THD & $\%$ & & $6 \%$ \\
\hline
\end{tabular}

\section{CONCLUSION}

It can be seen from the simulation results that the THD of source currents is greatly reduced and the unbalance of source currents is greatly improved. What's more, the neutral current RMS is reduced to less than 1A. So we can draw a conclusion that four leg shunt active power filter based on LCL filter which using capacitive current feedback control strategy has strong ability of harmonic and neutral current compensation. LCL filter based on capacitive current feedback control strategy can not only effectively suppress resonance but also avoid consuming active power, which will greatly improve efficiency of the four leg shunt active power filter. Then it will provide the basis for further practical application of the proposed algorithm.

\section{REFERENCES}

[1] Zhang Xing, Zhang Chongwei. PWM Rectifier And Its Control. Machinery Industry Press: Bei Jing, pp. 256-269, 2012.

[2] Chen Yao Jin Xinmin Tong Yibin. Grid-side LCL-filter of three-phase voltage source PWM rectifier. Transactions Of China Electrotechnical Society, 22(9), pp. 1-3, 2007.

[3] Qiu Zhiling, Yang Enxing Kong Jie. Current loop control approach for LCL-based shunt active power filter. Proceedings of the CSEE, 29(18), pp. 2-4, 2009.

[4] Guo Weifeng Xu Dianguo Wu Jian. Novel Control Method for LCL active power filter. Proceedings of the CSEE, 30(3), pp. 1-4, 2010.

[5] Wu Jian, He Na Xu Dianguo. Application of repetitive control technique in shunt active power filter. Proceedings of the CSEE, 28(18), pp. 2-3, 2008.

[6] Xu Zhiying, Xu Aiguo Xie Shaojun. Dual-loop grid current control technique for grid-connected inverter using an LCL filter. Proceedings of the CSEE, 29(27), pp. 1-2, 2009.

[7] Wu Jian, Xu Dianguo He Na. Research of shunt active power filter based on LCL filter. Electric Power Automation Equipment, 27(1), pp. 2-4, 2007.

[8] Pekik Argo Dahono. A Control Method to Damp Oscillation in the Input LC filter of AC-DC PWM Converters. Power Electronics Specialists Conference, IEEE Annual Cairns. Australia. pp. 1630-1635, 2002.
[9] Fritz Schimpf, Lars E Norum. Grid connected Converters for Photovoltaic State of the Art, Ideas for Improvement of Transformerless Inverters. Nordic Workshop on Power and Industrial Electronics: Norway, pp. 56-65, 2008. 